\title{
Activation of Single Neurons in the Rat Nucleus Accumbens during Self-Stimulation of the Ventral Tegmental Area
}

\author{
M. Wolske, ${ }^{1}$ P.-P. Rompre, ${ }^{2}$ R. A. Wise, ${ }^{2}$ and M. O. West ${ }^{1}$ \\ 'Department of Psychology, Rutgers, the State University, New Brunswick, New Jersey 08903 and ${ }^{2}$ Center for Studies in \\ Behavioral Neurobiology and Department of Psychology, Concordia University, Montreal, Quebec, Canada H3G 1M8
}

Single neurons $(n=76)$ were recorded in the nucleus accumbens septi (NAS) of rats self-stimulating the ipsilateral medial forebrain bundle (MFB) at the level of the ventral tegmental area (VTA). Responses evoked by rewarding trains of stimulus pulses fell into five categories. The first category ( $40 \%$ of the sample) was characterized by a single discharge at invariant latency in response to individual pulses of the train, and hence was termed "tightly time locked" (TTL). Two TTL neurons were collision tested, and both showed collision, suggesting that self-stimulation of the VTA may involve antidromic, and thus direct, activation of a substantial number of NAS axons. The second category (26\%) was characterized by discharges that varied in latency from pulse to pulse and hence was termed "loosely time locked" (LTL). Responses of the remainder of the sample showed no coupling to individual pulses but were categorized based on general firing patterns during the train: excited $(7 \%)$, inhibited $(4 \%)$, and no change $(23 \%)$. Irrespective of category, immediately after the self-stimulation session, the likelihood of evoked discharge at monosynaptic latency by single pulse stimulation of the ipsilateral fimbria was reduced (relative to pre-session level), concurrent with elevations in mean firing rate and motor activity.

NAS neurons thus exhibit vigorous activation, apparently both antidromically and orthodromically, in response to VTA self-stimulation. The responses of certain LTL and TTL neurons increased as a function of pulse number in the train, suggestive of integrative mechanisms important for brain stimulation reward. Conduction velocities of directly activated (TTL) axons (0.41-0.65 $\mathrm{m} / \mathrm{sec})$ were slower than those previously reported for first-stage, reward-relevant axons. Nonetheless, an implication of direct activation of NAS (and other MFB) axons is that rewarding stimulation triggers action potentials that could invade all axonal branches, including those between the stimulation site and the soma, and send synaptic signals to target neurons. Such signals from NAS neurons could contribute to the increased motor behavior accompanying MFB self-stimulation, and/or could interact with dopamine-mediated signals projected to the NAS from reward circuitry.

\footnotetext{
Received Mar. 10, 1992; revised June 9, 1992; accepted June 24, 1992.

This work was supported by NIDA Grant DA 04551, NSF Grant BNS-8708523, and U.S. Public Health Service Grant RR 07058 to M.O.W., and by NIDA Grant DA 01720 to R.A.W.

Correspondence should be addressed to M. O. West, Department of Psychology Rutgers University, New Brunswick, NJ 08903.

Copyright (C) 1993 Society for Neuroscience $0270-6474 / 93 /$ I 30001-12\$05.00/0
}

IKey words: brain stimulation reward, self-stimulation, medial forebrain bundle, ventral tegmental area, single-unit recording, nucleus accumbens, fimbria, hippocampus]

Animals rapidly learn to perform a variety of operant tasks in order to obtain electrical stimulation of the medial forebrain bundle (MFB). Considerable evidence suggests that responsiveness to brain stimulation reward (BSR) is sensitive to changes in the function of central dopamine (DA) neurons (Wise and Rompre, 1989). Among the several forebrain nuclei innervated by DA neurons, the nucleus accumbens septi (NAS) appears to play an important role in reward processes. Neurochemical studies have shown increased DA levels in the NAS following food consumption (Hernandez and Hoebel, 1988; Radhakishun et al., 1988; Joseph and Hodges, 1990), during administration of drugs abused by humans (Di Chiara and Imperato, 1988; Hernandez and Hoebel, 1988), and during self-stimulation of the MFB (Nakahara et al., 1989; Blaha and Phillips, 1990). Amphetamine (Hoebel et al., 1983) and electrical stimulation (Prado-Alcala and Wise, 1984) are self-administered directly into the NAS. Intra-accumbens amphetamine increases the rewarding impact of MFB self-stimulation (Colle and Wise, 1988). In contrast, the rewarding efficacy of MFB self-stimulation is decreased by pharmacologic blockade of DA receptors via microinjection into the NAS, but not other DA terminal fields (Stellar and Corbett, 1989). Moreover, 6-hydroxydopamine depletions of NAS DA attenuate MFB self-stimulation (Stellar and Corbett, 1989), block acquisition of amphetamine self-administration (Lyness et al., 1979), block maintenance of amphetamine (Lyness et al., 1979) and cocaine (Roberts et al., 1980; Pettit et al., 1984) self-administration, and block increased responding for conditioned reinforcement produced by intra-accumbens amphetamine (Taylor and Robbins, 1984, 1986).

While pharmacological studies strongly suggest that DA transmission in the NAS plays an important role in BSR, experiments using psychophysical methods adapted for studying self-stimulation have provided evidence that axons of DA neurons do not constitute a significant portion of the directly stimulated, first-stage axons. The latter have been shown to (1) be small in diameter and myelinated, (2) exhibit refractory periods in the range of $0.4-1.2 \mathrm{msec}$, (3) exhibit conduction velocities in the range of $1-8 \mathrm{~m} / \mathrm{scc}$, and (4) descend toward the mesencephalon, all of which are characteristics incompatible with those of ascending DA neurons (Yeomans, 1979; Yim and Mogenson, 1980a,b; Bielajew and Shizgal, 1982, 1986; Yeomans et al., 1988; Shizgal et al., 1989). It has been suggested that descending reward-relevant axons transsynaptically activate DA neurons 
(Wise, 1980; Yeomans, 1982; Bielajew and Shizgal, 1986), which in turn may produce a rewarding effect, in part, by modulating the activity of NAS neurons via robust ascending projections (Ungerstedt, 1971; Yim and Mogenson, 1980a; Totterdell and Smith, 1989; Sesack and Pickel, 1990). Using the BSR model, the objective of the present study was to provide an initial characterization of single-cell activity in the NAS during selfstimulation of the MFB at the level of the ventral tegmental area (VTA). Specifically, two primary questions were addressed. First, are NAS neurons synaptically activated, at latencies suggestive of disynaptic or polysynaptic input from reward circuitry? Second, because some NAS axons descend in the MFB to terminate in the VTA (Nauta et al., 1978) on DA neurons (Yim and Mogenson, 1980b), thus potentially satisfying one criterion of first-stage axons, are NAS neurons antidromically activated? Stimulation of axons results in both antidromic and orthodromic nerve impulses, and thus antidromic responses identify neurons whose fibers might carry directly activated, reward-relevant signals orthodromically toward the mesencephalon.

Preliminary results have been previously reported (Wolske et al., 1990).

\section{Materials and Methods}

Subjects. Adult, male Long-Evans rats (Charles River Laboratory) weighing $350-400 \mathrm{gm}$ at timc of surgery werc housed individually, given ad lib food and water, and maintained on a reversed $12 \mathrm{hr}$ light cycle (on 20:00, off 08:00) so that daily experiments were conducted during their active period.

Surgery. Rats were surgically implanted using modifications of a technique described previously (Deadwyler et al., 1979; West and Woodward, 1984). Rats were anesthetized with sodium pentobarbital $(50 \mathrm{mg} /$ $\mathrm{kg}$, i.p.), and a microelectrode drive (microdrive) base was surgically implanted on the (level) skull above the right nucleus accumbens at 2.2 $\mathrm{mm} \mathrm{AP}$ and $1.5 \mathrm{~mm} \mathrm{ML}$ relative to bregma (Paxinos and Watson, 1986). A bipolar stimulating electrode $(0.005$ inch Teflon-insulated stainless steel wire) was implanted in the ipsilateral fimbria $(-2.2 \mathrm{~mm}$ AP and $2.8 \mathrm{~mm}$ ML from bregma, $4.2 \mathrm{~mm}$ DV from skull). A monopolar stimulating electrode $(0.01$ inch Teflon-insulated stainless steel wire) was implanted in the ipsilatcral VTA ( $5.8 \mathrm{~mm}$ AP and $0.6-0.8 \mathrm{~mm}$ ML from bregma, $7.8-8.1 \mathrm{~mm}$ DV from the cortical surface). The tip of the VTA stimulating wire was sharpened to a point $\left(15^{\circ}\right)$ whose uninsulated conical surface area was $0.453 \mathrm{~mm}^{2}$ (tip length, $1.0 \mathrm{~mm}$ ). A tinned copper wire ( 22 or 26 gauge) wrapped around three skull screws posterior to bregma was used as the return path from the VTA stimulating electrode. Following surgery, rats were given a 1 week recovery period before testing.

Recording chamber. Experiments were performed in a clear Plexiglas recording chamber (L $35 \mathrm{~cm} \times W 17 \mathrm{~cm} \times \mathrm{H} 40 \mathrm{~cm}$ ). A speaker, through which a computer-controlled, $1000 \mathrm{~Hz}, 60 \mathrm{~dB}$ tone could be delivered, was positioned above the chamber at one end. At the same end of the chamber, a black Plexiglas lever protruded through a hole in a moveable, clear Plexiglas wall such that the length of lever available to the animal could bc varicd. Once animals had been conditioned to lever press, the wall was positioned so that only the paw could contact the lever. A second moveable wall, made of black Plexiglas, could be placed in front of the lever when it was desirable to deny the animal access to the lever. A low-level room light remained lit throughout the experiment to allow visual observation by the experimenter.

Stimulation. Each lever press resulted in the immediate delivery of one train of DC pulses ( $0.1 \mathrm{msec}$ pulse duration, $0.5 \mathrm{sec}$ train duration) to the VTA stimulating electrode. Maximum pulse frequency was 33 $\mathrm{Hz}$ (to permit analysis of firing between pulses; see below), resulting in a maximum of 16 pulses per train. During the first recording in each animal, a single stimulus current was identified as the lowest (threshold) current required to maintain lever pressing ( $>100$ presses $/ \mathrm{min}$ ). Reductions from threshold of less than $10 \%(0.03 \mathrm{~mA})$ resulted in cessation of lever pressing. This thrcshold valuc was the only stimulus current used throughout the study. For the four animals, stimulus current ranged from 0.3 to $0.5 \mathrm{~mA}$. Stimulus pulses were delivered by computer-controlled Grass SD9 stimulators.
Recording. Each recording day, the microdrive, equipped with a tungsten recording microelectrode (1-10 M $\Omega$; Frederick Haer), was attached to the animal, without anesthesia, and the electrode was lowered through cortex and striatum. To ensure that only NAS neurons were studicd, each neuron was tested for responsiveness to single pulse stimulation of the fimbria. Since subicular inputs project (via the fimbria) heavily to the NAS but only sparsely to the striatum (Groenewegen et al., 1987; Mogenson, 1987), only those neurons activated by, or bracketed dorsally and ventrally by neurons activated by, fimbria stimulation at monosynaptic latencies $(5-11 \mathrm{msec})$ were studied (DeFrance et al., 1985). Extracellular action potentials were led through a harness and comutator, amplified, filtered ( $1-9 \mathrm{kHz}$ bandpass), and sent to the computer (AST 386-C), which controlled all phases of the experiment (DISCOVERY software, Brainwave Systems Corp).

After the last recording in each animal, an electrolytic lesion $(0.05$ $\mathrm{mA}, 10 \mathrm{sec}$ ) was made with a 0.01 inch stainless steel insulated wire mounted in the microdrive to verify the placement of recording electrodes histologically. Cells recorded at depths not verified to be in the NAS were excluded from the sample. Electrolytic lesions were also made through fimbria and VTA stimulating electrodes to verify placement.

Procedure. After a neuron in the NAS was isolated, the animal was allowed access to the lever. If lever pressing did not commence within 2 min, up to five "priming" trains were delivered noncontingently, after which all rats began pressing. Each neuron was studied for 5 min of lever pressing (150-200 trains). Afterward, the Plexiglas wall was replaced to deny access to the lever. The electrode was then lowered to record additional NAS neurons similarly.

One measure of NAS activity was to compare firing during the train ( $0.5 \mathrm{sec}$ duration) with that during the $0.5 \mathrm{sec}$ period immediately preceding each train (see Data analysis, below). High rates of lever pressing (known to exceed three per second in self-stimulating rats) would interfere with this measure. This was prevented in three animals by using a fixed-interval $1.5 \mathrm{sec}$ schedule, ensuring a $1 \mathrm{sec}$ interval without stimulation following each train. Within five sessions ( $\sim 5000$ trials), animals exhibited a response scallop typical of fixed-interval schedules, after which recording commenced. A second strategy was to use a tone discrimination paradigm for the fourth animal. A tone $(1 \mathrm{kHz}, 65 \mathrm{~dB}, 7$ sec limited hold) signaling the availability of reward was presented at irregular intervals (range, 3-15 sec). The first press after tone onset resulted in cessation of the tone and delivery of one train. This animal required six sessions (approximately 4500 trials) to reach criterion (less than $10 \%$ incorrect presses between tone presentations) before recording commenced.

A second measure of NAS activity was the firing evoked by single pulses within each train. In order to allow this analysis, pulses were delivered at frequencies below $33 \mathrm{~Hz}$, providing a minimum interpulse interval of $30 \mathrm{msec}$.

Additional tests were performed on some neurons. Two NAS neurons were tested to assess whether the VTA-evoked discharge was antidromic, by means of the collision test. Immediately after the self-stimulation session, a window discriminator (World Precision Instruments model 121) was used to discriminate the neuronal waveform (separately from the discrimination performed by BRAINWAVE during the session; see next section). The output of the discriminator triggered the VTA stimulator to deliver one pulse identical to the pulses used during the session. A further test (20 neurons) was to assess alterations in NAS neuronal responsiveness to monosynaptic input from the hippocampus. This consisted of delivering approximately 50 fimbria pulses $(0.33 \mathrm{~Hz}) \mathrm{im}$ mediately before and after the self-stimulation session. A single stimulus intensity was selected that evoked neuronal discharges with approximately a $50 \%$ likelihood (range, $0.5-6.0 \mathrm{~mA} ; 0.1 \mathrm{msec}$ duration).

Data analysis. Using BRAINWAVE software, neuronal waveforms were digitized (32 kHz sampling frequency) and time stamped as they occurred, and stored for off-line analysis. Different waveforms recorded at single electrode positions were separated based on specific parameters. These were peak amplitude, valley amplitude, overall amplitude, duration (peak to peak), and polarity. The boundaries for each parameter were selected so as to yield pure neuronal waveforms and to reject stimulus artifact and other artifacts (i.e., related to grooming, chewing, etc.). Waveforms recorded throughout the time course of each experiment, and their parameters were displayed to ensure that no change in recorded signal occurred as a function of time, due to a spurious shift in electrode position.

Pcristimulus histograms (PSHs) were generated for each neuron. Since each count in the PSH corresponded to one occurrence of the waveform of that neuron, PSHs were free of all artifact (including stimulus artifact). Each histogram represented the summed activity of the neuron across 
approximately 150 train deliveries during a 5 min session. Two PSHs with different time bases were used to study each neuron's response to VTA self-stimulation. One PSH displayed neural firing during the 250 $\mathrm{msec}$ prior to train delivery, the $500 \mathrm{msec}$ of train delivery, and the 750 msec following the end of the train (total time base, $1.5 \mathrm{sec}$ ). Numerical data derived from these histograms were analyzed statistically and also were analyzed to quantify changes in evoked discharge as a function of increasing pulse number in the train. A second PSH displayed neuronal discharges on an expanded time base showing activity forward $50 \mathrm{msec}$ and backward $50 \mathrm{msec}$ from individual pulses of the train. All pulses from each train were summed across all trains ( 16 pulses per train $x$ 150 trains $=2400$ sweeps). Finally, PSHs were used to display monosynaptic responses to fimbria stimulation ( $50 \mathrm{msec}$ time base). "Spontaneous" firing rates were calculated from PSHs of longer time base displaying firing $1.5 \mathrm{sec}$ prior to each fimbria pulse (delivered once per $3 \mathrm{sec}$ ).

Terminology. The baseline ("base period") firing rate was the mean rate (in $\mathrm{Hz}$ ) during the $0.5 \mathrm{sec}$ period immediately prior to train delivery. "Train period" firing rate was the mean rate during the $0.5 \mathrm{sec}$ of train delivery. During the train period, an additional measure, termed "evoked period" firing rate, was determined for neurons exhibiting evoked discharges time locked to individual pulses. A "post-period" firing rate was calculated as the mean rate during the $0.5 \mathrm{sec}$ period after the end of the train.

Comparison of firing rates between these periods was based on a ratio that was calculated for each neuron as follows. For any two periods being compared, the firing rate of one period was divided by the summed firing rates of both periods. For example, the "evoked period:base period firing ratio" was the ratio of evoked period firing to the sum evoked period firing + base period firing. Ratios thus were limited to a range between 0 and 1 . These ratios evenly weighted increases and decreases, and minimized variance in firing rate among neurons, both of which were necessary for statistical analysis. Classification of non-time-locked neurons was made arbitrarily, based on train period:base period firing ratios. That is, neurons with a ratio between 0.33 and 0.66 were classified as no change. Those above 0.66 (i.e., firing during the train period was more than twice that of base period) were classified as excited, and those below 0.33 (i.e., train period firing was less than half that of base period firing) were classified as inhibited.

Statistical analysis. Version 6.06 of sAS (SAS Institute Inc.) was used to perform statistical analyses on an IBM 3081 mainframe computer. $T$ statistics were generated using a $t$ test for unequal variances, except as noted in the Results. No analyses were performed when there were fewer than five observations for a particular independent variable.

\section{Results}

Neuronal activity in the sample

Histological analysis confirmed that all neurons $(n=76)$ recorded from the four animals were located in the NAS (described below). Twenty-three of the 76 neurons exhibited firing rates too low to allow analysis (never exceeding $0.3 \mathrm{~Hz}$ ) and were not analyzed further. For 53 neurons analyzed, base period firing was not different from post-period firing $[T(84.3)=-0.72]$. In contrast, train period firing (including evoked period firing for time-locked responses) was significantly different from base period firing $[T(47.5)=-3.71 ; p<0.001]$ and from post-period firing $[T(48.1)=3.61 ; p<0.001]$. Therefore, further analysis of train period firing was undertaken.

\section{Categorization of neurons by PSH topography}

Visual inspection of PSHs across the sample revealed diverse but recurring topographies of neuronal response to self-administered trains of VTA stimulation. This prompted classification of each neuron into one of five categories: loosely time locked (LTL), tightly time locked (TTL), excited, inhibited, and no change. Except where noted, neuronal data did not differ across rats, and data therefore were pooled.

LTL neurons. Fourteen neurons showed excitatory evoked responses that were time locked to individual pulses in the train, at latencies that varied from one pulse to the next. Thus, the duration of the response displayed in the PSH was several milliseconds. Such responses were termed LTL and are consistent with synaptic activation. Across the 14 LTL neurons, a broad range of response topographies were exhibited. Response magnitudes of the 14 LTL neurons, in terms of evoked period:base period firing ratio, ranged from 0.52 to 0.96 (where 0.96 represents an increase of $>20$-fold in the evoked period; Fig $1 k$ ). Response durations ranged from 8 to $18 \mathrm{msec}$. Response latency ranged from $17 \mathrm{msec}$ (Fig. 1c) to $35 \mathrm{msec}$ (Fig. 11), the latter exceeding the interpulse interval (seen also in Fig. $1 k$, which illustrates that two responses occurred after the final pulse delivery). One exception was observed, that is, an LTL neuron (Fig. 1c) that responded at a much shorter latency ( $4 \mathrm{msec})$ than the others. This short-latency discharge was present in PSHs (not shown) displaying the response to only the first pulse of the train; moreover, PSHs synchronized to the last pulse of the train showed the short-latency response but did not show a second, long-latency ( $>33 \mathrm{msec}$ ) response (as seen for the neuron in Fig. $1 k, l$ ).

Four L'IL neurons exhibited distinct changes in evoked period firing as a function of pulse number in the train. In all four cases, responsivencss incrcascd as the train progressed. In cach case, the number of discharges in the evoked period increased in a nearly linear manner. To obtain a simple quantification of these increases, the response to the last pulse was compared with that to the first. Increases shown by the four neurons were $100 \%$ (Fig. $1 b$ ), 114\%, 155\%, and $950 \%$ (Fig. $1 k$ ). PSHs of the remaining $10 \mathrm{LTL}$ neurons exhibited no visible change in evoked period firing as a function of pulse number (e.g., Fig. le,h).

During the period between time-locked evoked responses within the train, firing decreased for five LTL neurons relative to the base period (range, $9-44 \%$ of base period firing). Figure $1 b$ illustrates an LTL neuron that exhibited this decrease. For this neuron, evoked period firing did not exceed base period firing, but consisted of a time-locked discharge within a period of generally decreased firing during the train (Fig. $1 c$ ).

During the post-period, one LTL neuron (Fig. $1 k$ ) exhibited an initial rebound excitation followed by a gradual recovery to the base period firing rate.

$T T L$ neurons. For 21 "tightly time-locked" neurons, a single discharge at an invariant latency characterized the response to individual pulses of the train, consistent with antidromic activation. That is, all evoked discharges occurred in one $1 \mathrm{msec}$ bin of the expanded PSH (Fig. 2). (For any given neuron, variations in response latency of less than $0.4 \mathrm{msec}$ resulted in the display of all neuronal discharges in one bin.) Latency to discharge for TTL neurons ranged from 11 to $16 \mathrm{msec}$.

Following the $5 \mathrm{~min}$ session of self-stimulation, two TTL neurons were tested for high-frequency following and collision, using a stimulus pulse identical to those used during self-stimulation. Both neurons followed paired stimuli separated by less than $2.0 \mathrm{msec}$; one showed a refractory period of $1.2 \mathrm{msec}$ (Fuller and Schlag, 1976). Both neurons also showed collision. The probability of evoked discharge for these two neurons was stable at 0.4 and 0.9 , respectively, when the collision interval was greater than the conduction time. When the collision interval was less than the conduction time, both neurons showed an abrupt cessation of evoked discharge. The conduction velocities for these two neurons were 0.41 and $0.43 \mathrm{~m} / \mathrm{sec}$ (latency, 16 and $15 \mathrm{msec}$, respectively). The range for all 21 TTL neurons, assuming that these invariant latency responses were also antidromic, was quite narrow, that is, from 0.41 to $0.65 \mathrm{~m} / \mathrm{sec}$.

Over half the TTL neurons (13 of $21,62 \%)$ were recorded 


\section{LOOSELY TIME-LOCKED}
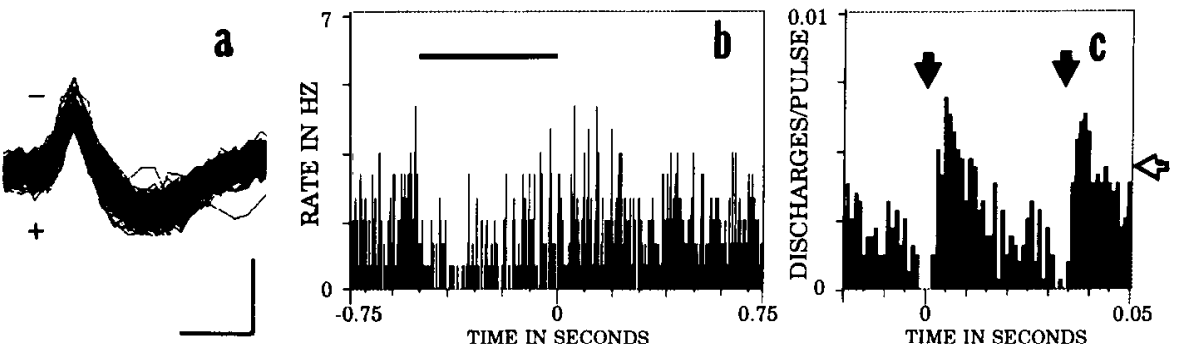

Figure 1. Four examples of LTL neuronal responses. Each neuron is represented in horizontal arrangement of three graphs (e.g., $a-c$ ). Graphs $a, d, g$, and $j$ are overlaid records of all occurrences of each neuron's extracellular action potential waveform during $5 \mathrm{~min}$ session of self-stimulation (negative is up; calibration: $0.2 \mathrm{msec}, 0.05 \mathrm{mV}$ ). Each occurrence of waveform corresponds with one count entered into each PSH at the right. Thus, PSHs contain no stimulus artifacts (which obscured neural waveforms for $1 \mathrm{msec}-i$.e., first bin after time 0 in right column). PSHs $b, e, h$, and $k$ show discharges during 250 msec prior to train of VTA pulses, $500 \mathrm{msec}$ of train delivery (horizontal bar), and $750 \mathrm{msec}$ following train delivery. All occurrences of last (16th) pulse in train (time 0 ) were used to generate PSH ( $\sim 150$ sweeps in each). The ordinate represents firing rate $(\mathrm{Hz})$ per bin ( $3 \mathrm{msec} / \mathrm{bin}$ ). PSHs $c, f, i$, and $l$ show responses to individual pulses in train. All pulses (1-16) in all trains of $5 \mathrm{~min}$ session (solid arrow at time 0 ) were used to generate PSHs $(-2400$ sweeps in each). The second solid arrow represents next pulse (2-16) in train. The ordinate represents, for each 1 msec bin, the number of discharges per stimulus pulse (i.e., likelihood, from 0 to 1 , of responding at a particular latency). The open arrow shows mean baseline firing rate (base period) converted into discharges per pulse, for reference to PSH at the left. Note that response latency in PSHs $k$ and $l$ was $35 \mathrm{msec}$, as shown by presence of two evoked responses after the end of train in $k$. Thus, response (peak) at the right in lis the true response to pulse at time zero; the peak at the left in $l$ is response to the preceding pulse.
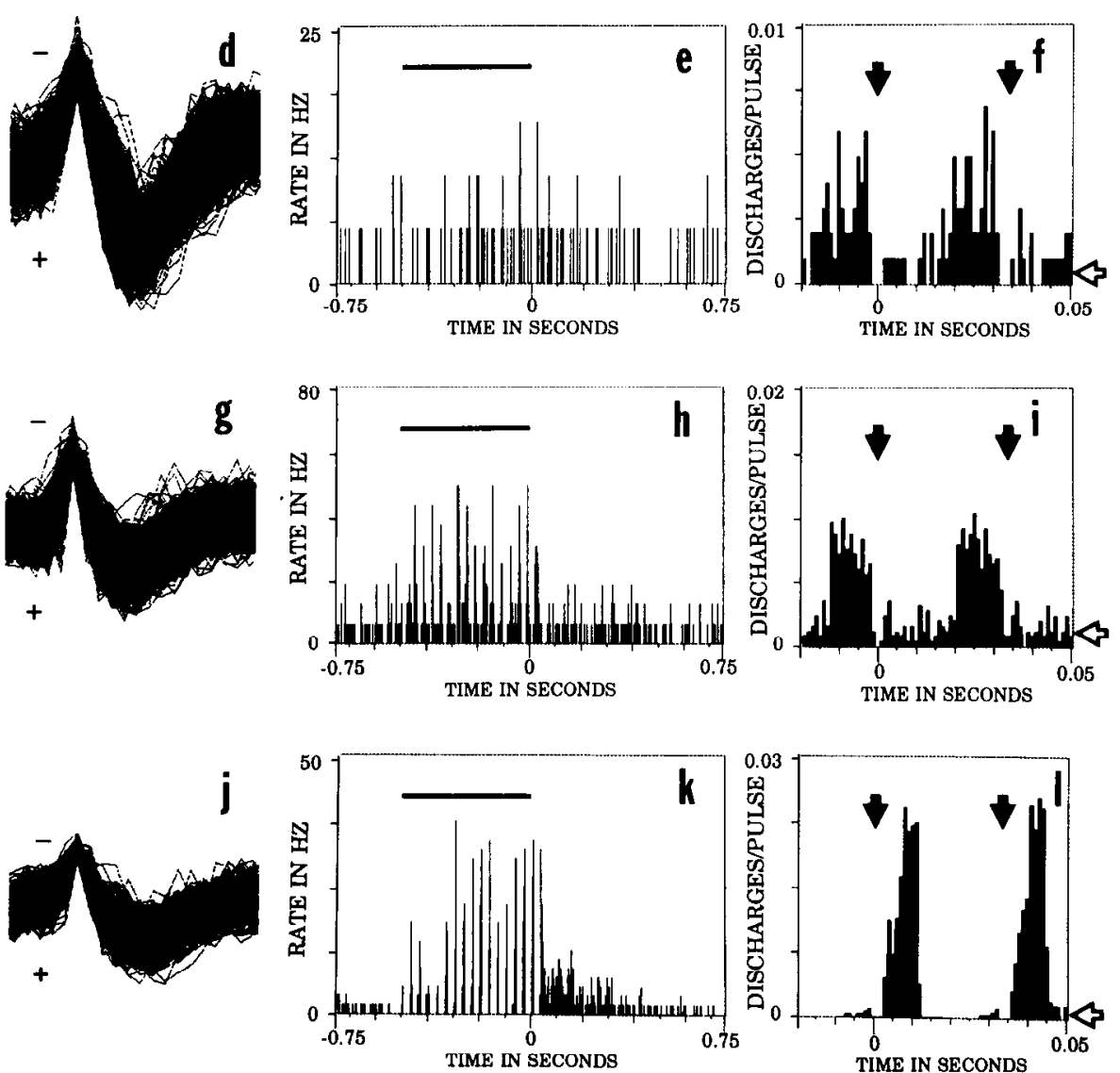

from one animal. These 13 neurons constituted $65 \%$ of the total neurons recorded from this animal. Placement of the VTA electrode for this rat was verified as $-4.80 \mathrm{~mm} \mathrm{AP}$ and $1.4 \mathrm{~mm}$ ML (from bregma) and $8.7 \mathrm{~mm}$ from skull surface. In contrast, a different animal exhibited only one TTL neuron $(8 \%$ of the total recorded from this animal). Placement of the VTA electrode was verified at $-6.04 \mathrm{~mm} \mathrm{AP}$ and $0.5 \mathrm{~mm} \mathrm{ML}$ (from bregma) and $8.8 \mathrm{~mm}$ from skull surface. Although all neurons from both animals were recorded from the central region of the AP extent of the NAS, recordings obtained from the latter animal (exhibiting one TTL response; see Fig. 5, track D) were lateral and ventral to those from the former (see Fig. 5, track C). Overall, 18 TTL neurons were observed medially ( $40 \%$ of all neurons recorded medially), whereas only 3 TTL neurons were observed laterally ( $10 \%$ of all neurons recorded laterally). Due to technical problems, histological verification of the VTA electrode placement for the other two animals could not be performed.
Evoked period firing rates were substantially higher than base period rates for TTL neurons. The evoked period:base period firing ratio ranged from 0.89 to 1.00 . That is, the smallest increase was greater than eightfold. The largest increase $(1.00$ ratio) reflected one neuron's absence of spontaneous firing in the base period.

The evoked period discharge of six TTL neurons changed as a function of pulse number in the train. In each case, the change took the form of a shift, within one to three pulses, from one fairly steady level of response to another. To obtain a simple quantification of these changes, the mean response to all pulses after the shift was compared with that to all pulses before the shift. (Onset of the shift ranged from pulse 4 to pulse 10 ). Five neurons showed increases of $54 \%$ (Fig. $2 e$ ), $63 \%$ (Fig. $2 h$ ), $80 \%$, $83 \%$, and $187 \%$, and one neuron showed a decrease of $64 \%$ (Fig. $2 b$ ). Of three neurons that were recorded simultaneously, one increased (Fig. 2e), one decreased (Fig. 2b), and one showed no change (not shown) across the train, suggesting that such changes 


\section{TIGHTLY TIME-LOCKED}
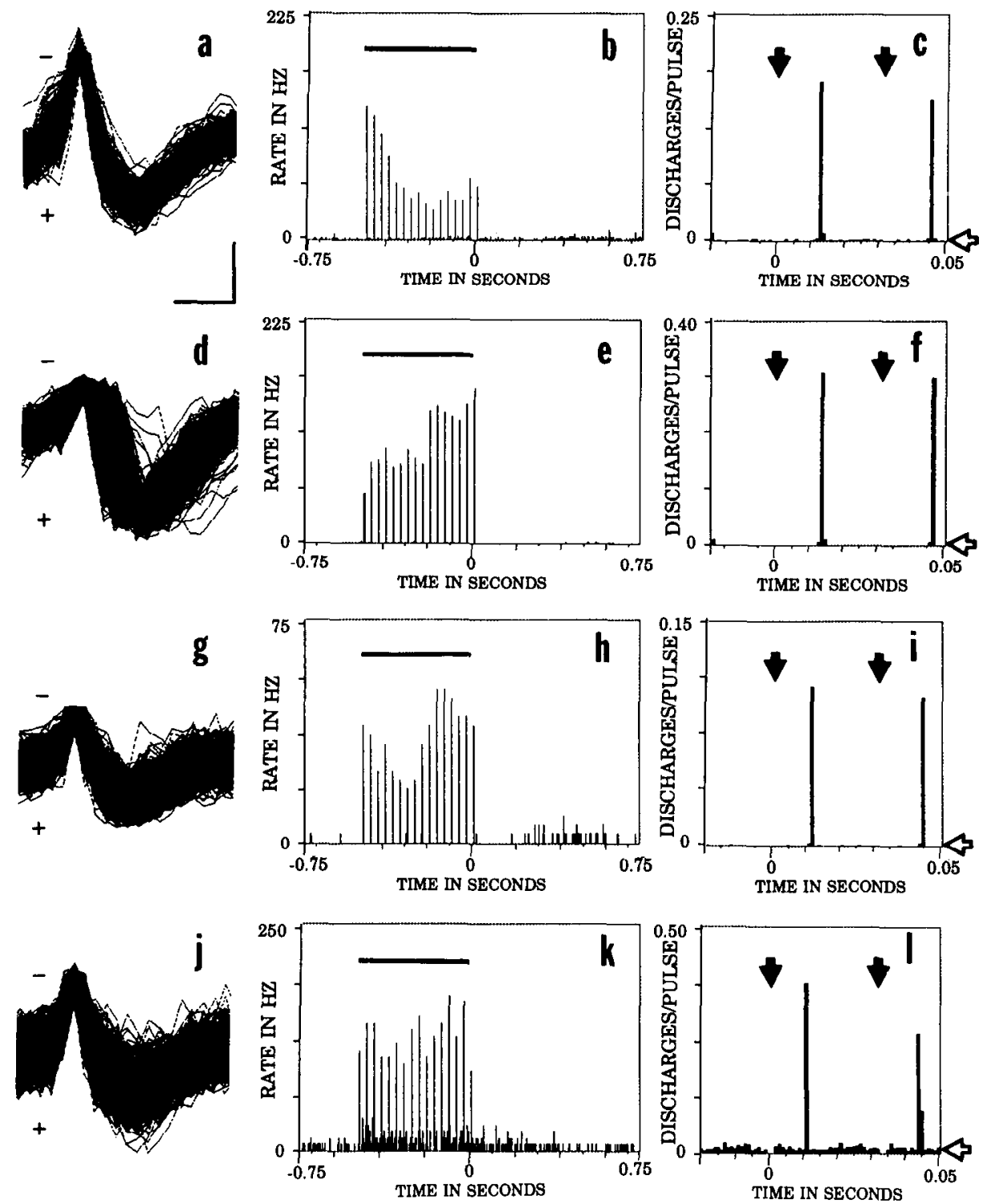

Figure 2. Four examples of TTL neuronal responses. TTL responses were characterized by invariant latency: all discharges occurred within one $1 \mathrm{msec}$ bin $(c, f, i$, and $l$ ). (Note that stimulus artifact is not displayed.) Different neurons responded at different latencies. Details are as in Figure 1. were not due to spurious fluctuations in pulse intensity during the train. The remaining 15 TTL neurons did not show any identifiable pattern of change in evoked firing across the train (e.g., Fig. $2 k$ ).

During the period between time-locked evoked responses within the train, four TTL neurons exhibited increased firing rates rclative to base period firing (range, $210-4200 \%$ of base period level), seven showed decreased firing rates (range, <1$46 \%$ of base period level), and seven did not change (no determination was possible for the remaining three neurons). Also, five TTL neurons exhibited changes during the post-period. The decreases over the course of the post-period on the part of three neurons appeared to represent recovery from elevated firing between evoked periods of the train (e.g., Fig. $2 k$ ). The increascs shown by the other two neurons appeared to represent rebound from suppressed firing between evoked periods of the train.

Non-time-locked neurons. Eighteen neurons exhibited general patterns of firing that were not time locked to individual pulses of the train. The responses of these neurons were categorized (see Materials and Methods) as excited $(n=4)$, inhibited $(n=$ 2 ), and no change ( $n=12)$. Figure 3 illustrates the responses of three excited neurons. Firing rates increased beginning approximately $25 \mathrm{msec}$ after the first pulse, continued throughout the duration of the train, and extended $100-400 \mathrm{msec}$ into the postperiod (Fig. $3 b, e, h$ ). Figure 4 illustrates the responses of the two inhibited neurons. Firing rates decreased beginning $35-60 \mathrm{msec}$ following the first pulse in the train, continued throughout the duration of the train, and extended $50-350 \mathrm{msec}$ into the postperiod. Neither excited nor inhibited neurons exhibited any change in responsiveness across the train period.

\section{Comparisons of the categories}

The mean firing rate for neurons in each catcgory is shown in Table 1. Orthogonal comparisons were made using base period firing as the dependent variable. Base period firing for LTL neurons was significantly higher than that of the other categories combined $[T(12.4)=2.33 ; p<0.05]$. Two LTL neurons showed unusually high base period firing rates $(11.27 \mathrm{~Hz}$ and $12.08 \mathrm{~Hz})$ 


\section{EXCITED}
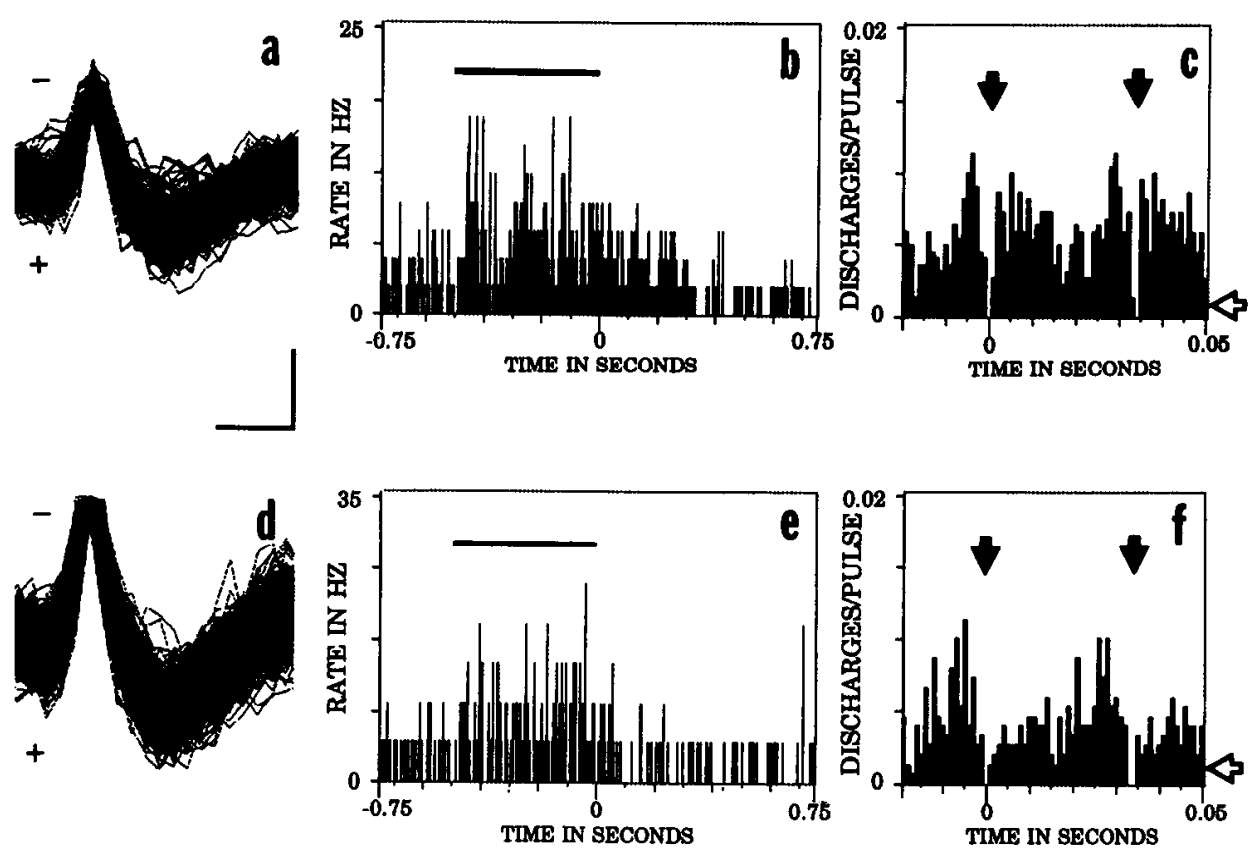

Figure 3. Three examples of excited, non-time-locked NAS neuronal responses. Evoked firing of excited neurons consisted of general increase during train period (horizontal bar over graphs $b, e$, and $h$ ) that showed no obvious synchrony to individual pulses (solid arrows in graphs $c, f$, and $i$ ). Details are as in Figure 1.
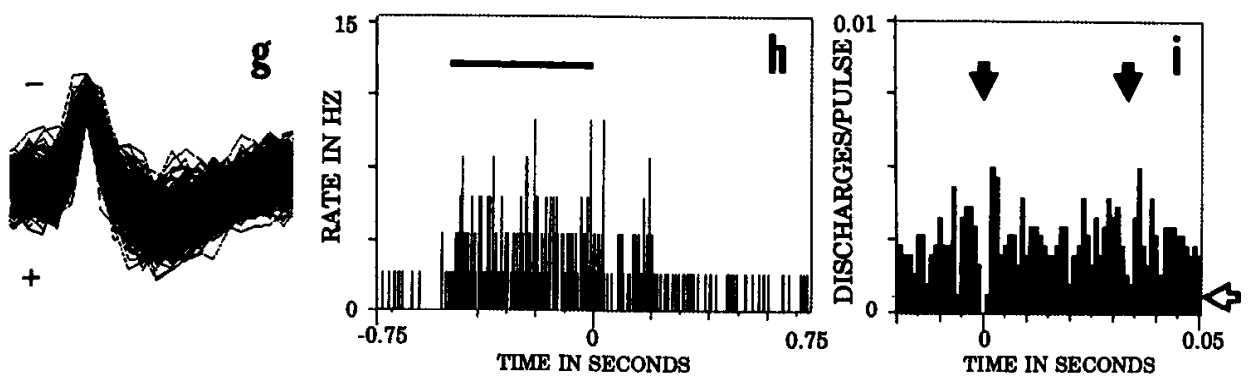

as compared with other LTL neurons $(0.65-4.53 \mathrm{~Hz})$ and the other categories. Base period firing of neurons showing no change was not different from that of excited, inhibited, and TTL neurons combined $[T(18.1)<1]$. No further comparisons were possible.

\section{Histology}

Of 76 neurons in the sample, 33 were located in the central region of the AP axis of the NAS, 5 were anterior, and 38 were posterior. Figure 5 shows the locations in the NAS of all neurons in the sample, in terms of response category.

\section{Comparison of pre-versus post-session levels of spontaneous} and fimbria-evoked firing

For 20 NAS neurons, spontaneous firing rate and response to fimbria stimulation (verified histologically) were measured immediately after the $5 \mathrm{~min}$ session of VTA self-stimulation and compared to pre-session levels. Mean spontaneous firing rate following the session was significantly increased (Fig. 6), from 2.15 to $2.69 \mathrm{~Hz}[T(19)=3.22 ; p<0.01$, paired $t$ test]. Concurrently, a significant decrease was observed in mean likelihood of evoking discharge at monosynaptic latency $(5-11 \mathrm{msec})$ by

single pulse stimulation of the ipsilateral fimbria, from 0.58 to 0.25 discharges/pulse $[T(19)=-3.24 ; p<0.01]$.

\section{Discussion}

These findings constitute the first characterization at the singlecell level in self-stimulating animals of neural activity in the NAS. The major conclusion of this study is that NAS neurons exhibit vigorous responses to self-administered trains of VTA

\section{Table 1. Mean firing rates $( \pm \mathrm{SEM})$ of the five categories during base, train, and post periods}

\begin{tabular}{lllll} 
& Period & & \\
\cline { 2 - 4 } Category & Base & Train & Post & $N(53)$ \\
\hline LTL & $3.5 \pm 1.1$ & $10.5 \pm 2.5$ & $4.6 \pm 1.6$ & 14 \\
TTL & $0.9 \pm 0.2$ & $42.1 \pm 10.2$ & $1.2 \pm 0.3$ & 21 \\
Excited & $1.0 \pm 0.3$ & $3.5 \pm 1.1$ & $1.3 \pm 0.4$ & 4 \\
Inhibited & $1.0 \pm 0.1$ & $0.3 \pm 0.1$ & $1.4 \pm 0.8$ & 2 \\
No change & $1.2 \pm 0.3$ & $1.0 \pm 0.3$ & $1.2 \pm 0.3$ & 12
\end{tabular}

For time-locked response categories, "Train" refers specifically to evoked period. $N=$ number of neurons in each category. 


\section{INHIBITED}
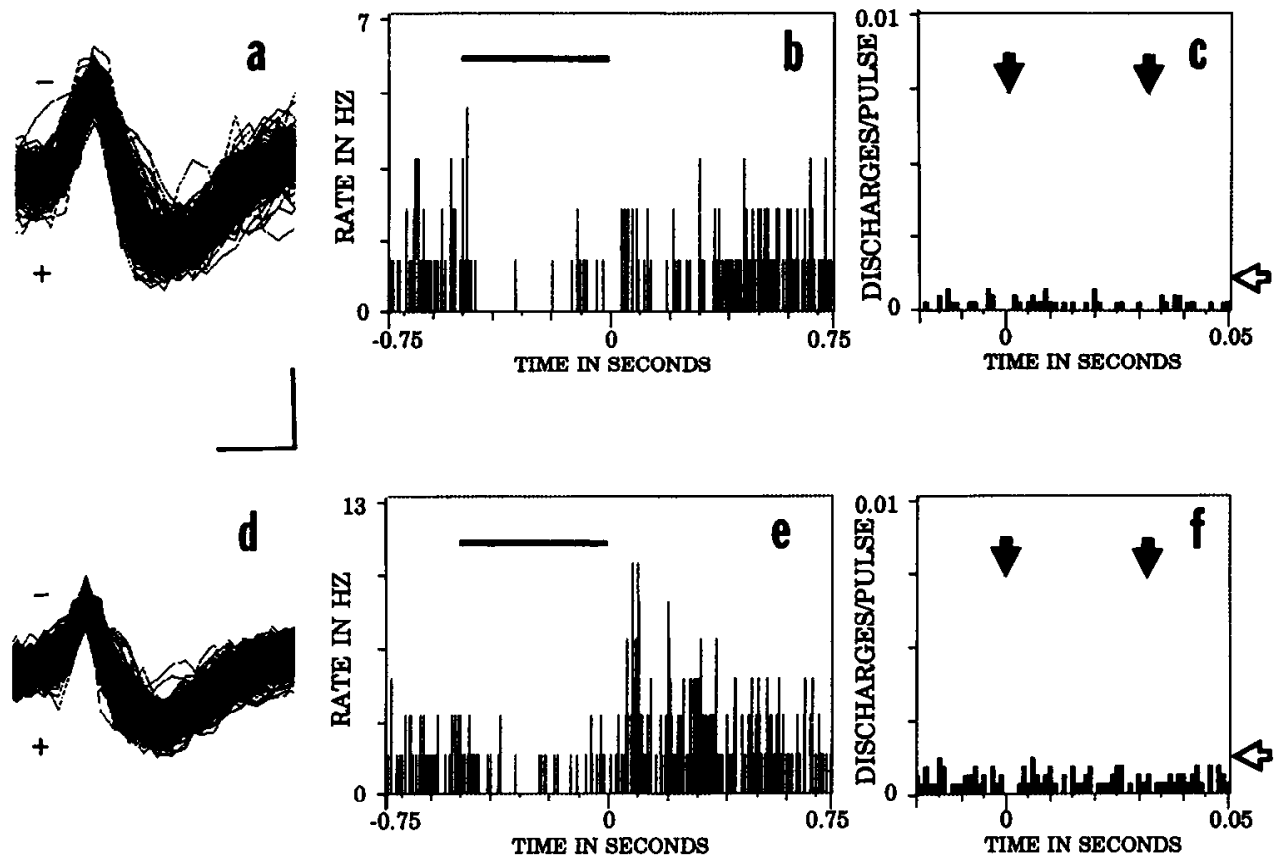

Figure 4. Graphs illustrating the two inhibited, non-time-locked neuronal responses. Evoked activity of inhibited neurons consisted of general decrease in firing during train period that showed no synchrony to individual pulses. The neuron at the top showed steady recovery during the post-period (graph $b$ ); the neuron at the bottom showed rebound/ recovery in post-period (graph $e$ ). Details are as in Figure 1.

stimulation. Although the magnitude of the responses, for example, Figures 1 and 2, might be an expected result of stimulating thc VTA, a major afferent and efferent of the NAS, such responsiveness was not predicted by the results of $2-{ }^{14} \mathrm{C}$-deoxyglucose (2-DG) autoradiographic studies by Gomita and Gallistel (1982) and Gallistel et al. (1985). These investigators found that 2-DG utilization was not altered in the NAS following a 45 min session of MFB stimulation. However, a recent study by Porrino et al. (1990) showed that 2-DG utilization was increased in the NAS following self-administered trains of MFB stimulation. These authors suggested that modifications in the 2-DG technique by Gallistel and colleagues accounted for the differences in the results. In agreement with the present findings, several other studies have demonstrated increased NAS activity in response to MFB stimulation, by means of a variety of methods, including acute electrophysiology (Rompre and Shizgal, 1986; Shizgal et al., 1989), acute (Gratton et al., 1988) and chronic (Blaha and Phillips, 1990) electrochemistry, microdialysis (Nakahara et al., 1989), and tyrosine hydroxylase activity (Phillips et al., 1987).

\section{Possible mechanisms mediating NAS responses to self- stimulation}

Based on the topography of PSHs, NAS responses to VTA selfstimulation were separated into four categories. These topographies were, in turn, based on neurophysiological and neurochemical principles.

TTL neurons all met the first criterion for demonstrating antidromic excitation, that is, that neuronal discharges be evoked at a constant latency across trials (variance of less than $0.1-0.5$ msec; Lipski, 1981). Indeed, the present rigid invariance in latency militates strongly against the alternative explanation, that TTL responses were mediated synaptically. A second test, con- sidered the most reliable measure of antidromic discharge (Fuller and Schlag, 1976), is the collision test. Both TTL neurons tested, using a stimulus pulse identical to those used during selfstimulation, showed collision. Both neurons also faithfully followed high-frequency $(>500 \mathrm{~Hz})$ stimulation, thus meeting all criteria for antidromic activation. These results provide strong evidence that some neurons (up to $40 \%$ of the present sample) in the NAS are antidromically, and thus directly, activated by self-stimulation of the VTA, consistent with anatomical (Nauta ct al., 1978) and electrophysiological (Maeda and Mogenson, 1980; Yim and Mogenson, 1980b) evidence for a descending projection from the NAS to the VTA.

LTL responses exhibited durations, evident in PSHs, ranging from 8 to $18 \mathrm{msec}$. Analysis of responses to single pulses (raster displays not shown) revealed either single or multiple discharges that varied in poststimulus latency from one pulse to the next. Such responses are consistent with synaptic activation. We cannot rule out the possibility that some recordings involved more than one neuron with waveforms indistinguishable from one another, using the present template matching technology. This could account for the variable latencies, as well as the high firing rates (in some cases), of LTL neurons. However, the long durations of the evoked response period (up to $18 \mathrm{msec}$ ) almost certainly do not represent the discharges of up to 18 indistinguishable, antidromically activated (TTL) neurons, each at a different latency. Therefore, the most important conclusion drawn from LTL discharges is sustained, that is, that they represent a distinct category of NAS responses mediated synaptically, not antidromically. Orthodromic transmission to the NAS could involve direct projections from the VTA (Ungerstedt, 1971; Beckstead et al., 1979; Nauta et al., 1978; Sesack and Pickel, 1990). Judging from the topographies of most LTL responses, fairly rapid on-off excitatory neurotransmission ap- 
Figure 5. Summary of locations of NAS neurons across animals. Top, Each column $(A E)$ illustrates dorsoventral positions of neurons within electrode tracks whose positions are shown in coronal planes at the bottom $(A-E)$. Each "track" represents one to three individual electrode penetrations at that location. Thus, each neuron can be visualized with respect to its location in the NAS, but not with respect to its spatial relation to other neurons. Each neuron is represented by letter designating its response category $(T, \mathrm{TTL} ; L$, LTL; $E$, excited; $I$, inhibited; $N$, no change; $U$, unidentified; -, neurons not meeting criteria for study; blank spaces represent absence of single cell activity). "Unidentified" neurons are those with firing rates too low to classify. The vertical scale (top right) is divided into $100 \mu \mathrm{m}$ intervals and labeled every 1.0 $\mathrm{mm} ; 0$ represents point of entry into NAS. Bottom, Tracks change from broken to solid line at point of entry into NAS. Ventralmost portions of some tracks (e.g., track $B$ ) were located in NAS shell. Numbers indicate AP distance (in $\mathrm{mm}$ ) from bregma (Paxinos and Watson, 1986). Each coronal plane is partial view of one hemisphere (medial at left; lateral at right). Hatched areas, anterior commissure. Tick marks on tracks are at 1.0 mm intervals.
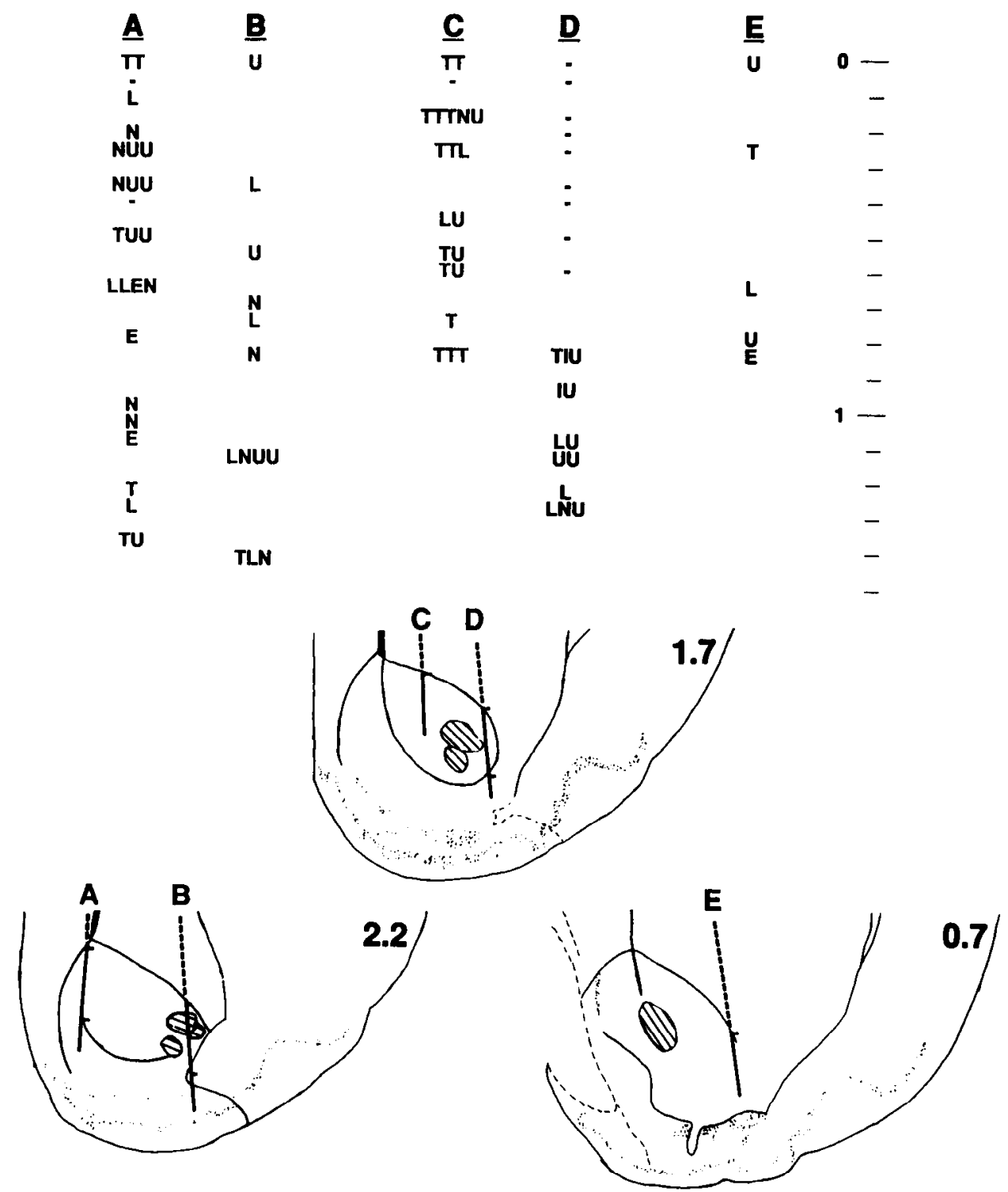

peared to be involved (Maeda and Mogenson, 1980; Thierry et al., 1980; Yim and Mogenson, 1980a). No conclusions can be drawn regarding the conduction velocities of axons mediating LTL responses (given an unknown number of synaptic delays), or whether these responses involve DA.

Non-time-locked changes in firing lasting throughout the train period were exhibited by excited and inhibited neurons, and also by certain LTL and TTL neurons during the period between time-locked evoked firing. Such patterns could reflect asynchronous polysynaptic input, or possibly the action of slowacting transmitters or modulators. Neurons in non-time-locked response categories may represent distinct populations of NAS neurons or may have been misaligned with the portion of the MFB activated in a given animal; a different alignment might produce time-locked discharges.

\section{Possible functions of NAS response patterns in self-stimulation}

Do these findings fit present conceptualizations of activity in reward circuitry during self-stimulation? According to the model advanced by Gallistel et al. (1981), action potentials are generated initially in a bundle of reward-relevant axons. These first- stage neurons make synaptic connections with second-stage neurons that integrate the signal. Integration may take place at one or more additional synaptic stages in the relevant circuitry, but ultimately the signal reaches a conversion site where the rewarding effect is generated.

Could the observed NAS firing patterns represent activity of first-stage neurons? Psychophysical methods adapted for studying self-stimulation have revealed that the axons of first-stage (directly activated) neurons are myelinated, descending axons (Bielajew and Shizgal, 1986) with conduction velocities of 1-8 $\mathrm{m} / \mathrm{s}$, diameters of $0.3-1.5 \mu \mathrm{m}$ (Bielajew and Shizgal, 1982), and refractory periods between 0.4 and $1.2 \mathrm{msec}$ (Yeomans, 1979). One category in this study consisted of neurons that were antidromically, and thus directly activated, that is, TTL neurons. In one case, a determination of refractory period was made, and this value, $1.2 \mathrm{msec}$, is within the appropriate range, as were values obtained from a portion of NAS neurons in acute studies (Rompre and Shizgal, 1986; Shizgal et al., 1989). TTL neurons are further implicated as candidates by studies indicating that some NAS axons descend in the MFB to terminate in the VTA (Nauta et al., 1978) on DA neurons (Yim and Mogenson, 1980b). 

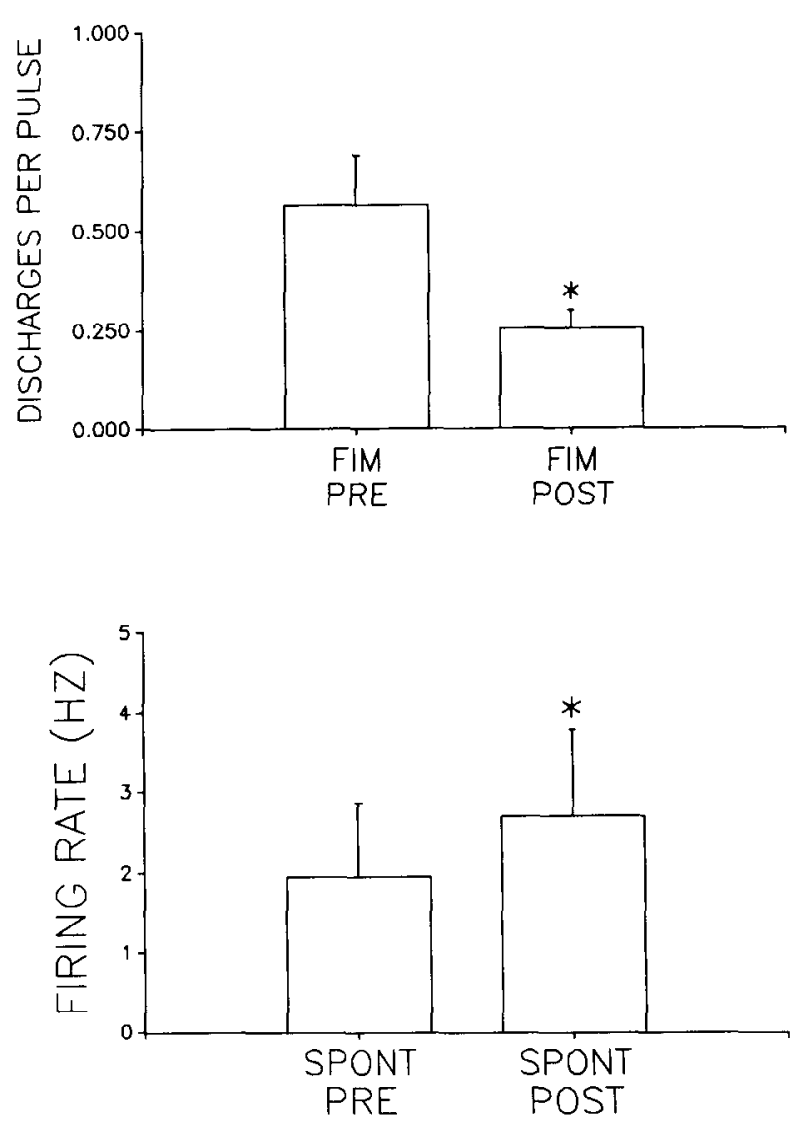

Figure 6. Concurrent increase in mean firing rate and decrease in fimbria-evoked discharge ( $n=20$ NAS neurons) immediately following session of VTA self-stimulation. Top, Mean number of discharges per pulse evoked at monosynaptic latency by single pulse stimulation of ipsilateral fimbria immediately before (PRE) and after (POST) session. Bottom, Mean spontaneous firing rate of same neurons during corresponding time periods. Asterisks indicate significant changes $(p<0.01)$ relative to pre-period.

Thus, these neurons project caudally to the brainstem and exhibit thresholds low enough to be excited by rewarding stimulation parameters. However, conduction velocities of TTL neurons ranged from 0.41 to $0.65 \mathrm{~m} / \mathrm{sec}-$ below the values determined for first-stage, reward-relevant axons in studies (Yeomans, 1989) using stimulus parameters similar to those used in the present study. Thus, TTL neurons do not meet all criteria for first-stage neurons (Shizgal et al., 1989).

Are the recorded neuronal responses consistent with the possibility of a role for the NAS at a later stage in reward circuitry? It is known that one or two brief $(0.1 \mathrm{msec})$ pulses are not sufficient to support self-stimulation, but that a train of several pulses is required. This suggests the need for an additive (integrative) process across the train of pulses, which might be evidenced as a change in the responses of neurons at an integrator site. The evoked discharge of 10 NAS neurons (of 33 examined) did show changes across the train. Nine (four LTL and five TTL neurons) of these 10 showed increased responsiveness, possibly reflective of an additive process. These changes did not appear to be due to unintended fluctuations in stimulus pulse intensity across the train (e.g., due to electrode polarization), because simultaneously recorded neurons showed changes in opposite directions (Fig. 2b.e). Moreover, since the response to each pulse was a summation across $>150$ trials, it was considered a reliable measure. Thus, some NAS neurons, particu- larly the LTL neurons, in which responses appeared to be orthodromic, exhibited a pattern that might be expected of neurons involved in the integration of rewarding signals. To our knowledge, this is the first such demonstration. Whether this pattern is unique to the NAS is an issue awaiting further study; no such pattern has been reported in electrophysiological studies of other structures (Rolls, 1971a,b; Segal and Bloom, 1976). Finally, it should be noted that changes across the train shown by TTL neurons, assuming these were antidromically activated, could possibly reflect changes in terminal excitability (cf. Ryan et al., 1986, 1989).

\section{Relevance of response patterns to DA transmission in the NAS}

Recent evidence strongly suggests that DA transmission is an important component of MFB self-stimulation. When DA levels are increased in the NAS through local injections of amphetamine during self-stimulation, reward, measured independently from motor performance, is enhanced (Colle and Wise, 1988). Conversely, when DA function is temporarily attenuated via local injection of neuroleptics into the NAS, reward, but not motor performance, is decremented (Stellar and Corbett, 1989). That this is a specific function of DA in the NAS and not other forebrain DA terminal fields is supported by the finding that local injections of neuroleptics into the striatum, amygdala, or prefrontal cortex do not affect reward (Stellar and Corbett, 1989). Complementary to these reports, electrochemical studies have shown that NAS DA levels correlate directly with MFB selfstimulation using both microdialysis (Nakahara et al., 1989) and in vivo voltametry (Blaha and Phillips, 1990). Taken together, these data provide strong support for a role of NAS DA in BSR (see also Wise and Rompre, 1989).

The question of whether DA or other neurotransmitters afferent to the NAS (Maeda and Mogenson, 1980; Yim and Mogenson, 1980a) are involved in actually mediating any of the present NAS response patterns was not addressed in this study. Nonetheless, the significance of these findings is that they were obtained during self-stimulation of the MFB, and therefore must be considered integral with the activity of a structure important for this behavior. Direct, antidromic activation of NAS neurons on an apparently large scale must almost certainly interact with putative reward-relevant dopaminergic activity in the NAS. For example, action potentials conducted antidromically to the NAS could invade short, probably GABAergic axon collaterals (Smith and Bolam, 1990) and potentially modify responses of neighboring neurons (Somogyi et al., 1981) to incoming synaptic signals from reward circuitry. Or, for example, synapses upon a TTL NAS neuron that are activated (orthodromically) by reward circuitry concurrently with antidromic activation of that same neuron could undergo changes, such as Hebbian potentiation. Such interactions could facilitate-or interfere withneural activity mediating MFB stimulation reward. Whatever the case, the inevitable conclusion is that, during self-stimulation of the MFB at the level of the VTA, NAS output includes the response patterns shown here, either separate from, or in combination with, any DA-mediated processing. Although the form and the effects of such interactions must remain speculative at present, knowledge of these NAS response patterns may prove necessary for ultimately understanding neural circuit activity underlying BSR.

Another implication of direct, antidromic activation of NAS neurons during MFB self-stimulation is that all target cells of antidromically activated neurons, not just those that are efferent 
to the stimulating electrode, may receive synaptic inputs via collateral projections. That is, rewarding stimulation triggers action potentials in directly activated axons both orthodromically and antidromically, the latter of which could potentially invade axonal branches that leave the main axon between the stimulation site and the soma. Presumably, this applies to all directly activated axons originating in the many nuclei, including the NAS, that contribute to the MFB (Nieuwenhuys et al., 1982). In addition, TTL firing was well within natural limits. TTL discharges showed an orderly relation to stimulus pulses (either one discharge or no discharge in response to each stimulus pulse, delivered at $33 \mathrm{~Hz}$ or less). Thus, TTL discharges did not represent aberrant neural firing, characteristic of epileptiform activity or high-frequency "injury discharge." Taken together, these observations suggest that signals projected orthodromically by branches of first-stage axons to target neurons, whether the latter are second-stage neurons of reward circuitry or not, are likely to be of consequence. For example, signals projected from NAS TTL neurons to targets in locomotor centers (Mogenson, 1987) could contribute to the robust stimulation of locomotor behavior that accompanies MFB self-stimulation. (Locomotor stimulation also could result from the apparently orthodromically mediated activity of LTL, excited, and/or inhibited neurons in the NAS.)

\section{Fimbria stimulation}

The decreased likelihood of evoking monosynaptic NAS discharges by stimulating the fimbria immediately following the session of VTA self-stimulation was not the result of a generalized decrease in excitability of NAS neurons, since mean firing rates were elevated at this time. A plausible explanation of this decrease derives from work reported by Yang and Mogenson (1986). They demonstrated that subicular neurons antidromically activatcd by stimulation of the $\mathrm{N} \Lambda \mathrm{S}$ exhibited an increased likelihood of being activated by NAS stimulation following trains of VTA stimulation. Their results suggested that the mechanism responsible for this effect was a D2 receptor-mediated increase in subicular terminal excitability: elevated DA levels, via D2 heteroreceptors, depolarized the subicular terminals in the NAS, resulting in presynaptic inhibition, that is, decreased release of neurotransmitter upon arrival of an orthodromic action potential at the subicular terminal. The present decrease in fimbriaevoked NAS neuronal discharge, which occurred within the same time interval (several minutes) following trains of VTA stimulation as did enhanced terminal excitability (Yang and Mogenson, 1986), could involve a similar depolarization of subicular terminals in the NAS. Indeed, a residual elevation in DA levels in the NAS during a similar time period after VTA selfstimulation was recently reported (Blaha and Phillips, 1990). Moreover, ultrastructural evidence indicates that the arrangement of dopaminergic terminals in the NAS could potentially modulate hippocampal synaptic input (Totterdell and Smith, 1989; Sesack and Pickel, 1990; cf. Freund et al., 1984). It has also been shown that activation of VTA neurons by opiates reduced NAS neuronal discharge evoked by fimbria stimulation, but this effect did not appear to be mediated by DA (Hakan and Henriksen, 1989). Other possible explanations cannot be ruled out; for example, increased activity of fimbria fibers after the session could have resulted in refractoriness to stimulation.

Anatomical projections from the NAS to the VTA have been demonstrated (Nauta et al., 1978; Maeda and Mogenson, 1980; Walaas and Fonnum, 1980). Their antidromic activation ap- peared to mediate the TTL responses of this study, two of which were confirmed by the collision test. One of the neurons showing collision, as well as 16 of 16 other TTL neurons tested, responded at monosynaptic latency to stimulation of the fimbria. These findings demonstrate that hippocampal neurons have a disynaptic route of accessing VTA neurons-potentially DA neurons, which have been shown to receive synaptic input from NAS axons (Yim and Mogenson, 1980b). The data (Fig. 6) suggest that the eflicacy of the connection from the hippocampus to the NAS and VTA may be reduced, at the level of the NAS, by activation of the VTA itself, with possible implications for limbic-motor integration (Lopes da Silva et al., 1984; Mogenson, 1987).

\section{Behavior}

Increased motor behavior (e.g., sniffing, gnawing, rearing, locomotor activity, head bobbing) was associated with self-stimulation. As typically observed during self-stimulation of the MFB (Olds and Milner, 1954; Trowill et al., 1969), these behaviors commenced upon delivery of the first VTA train of each session and continued for 3-4 min after the last train delivery. Mean firing rates of NAS neurons during this 3-4 min period following the session were significantly higher than those immediately prior to self-stimulation. (It was not possible to assess mean firing rates during the session itself.) Finding elevated firing rates of NAS neurons during elevated motor behavior is consistent with the previous observation in our laboratory that $95 \%$ of NAS neurons fired faster during locomotion than during rest (West and Wolske, 1987). Increased firing of NAS neurons following VTA self-stimulation may be related, among several possibilities, to concurrent residual elevation in DA levels in the NAS following VTA self-stimulation (Blaha and Phillips, 1990). This may implicate elevated firing of NAS neurons as a mechanism by which DA action at the level of the NAS stimulates motor behavior (cf. Kelley et al., 1989; Delfs et al., 1990). Alternatively, if VTA stimulation results in residual DA elevation within the VTA as well, autoreceptor-mediated inhibition of VTA DA neurons could, in turn, disinhibit NAS neurons (White and Wang, 1986).

\section{References}

Beckstead RM, Domesick VB, Nauta WJH (1979) Efferent connections of the substantia nigra and ventral tegmental area in the rat. Brain Res 175:191-217.

Bielajew C, Shizgal P (1982) Behaviorally derived measures of conduction velocity in the substrate for rewarding medial forebrain bundle stimulation. Brain Res 237:107-119.

Bielajew C, Shizgal P (1986) Evidence implicating descending fibers in self-stimulation of the medial forebrain bundle. J Neurosci 6:919929.

Blaha CD, Phillips AG (1990) Application of in vivo electrochemistry to the measurement of changes in dopamine release during intracranial self-stimulation. J Neurosci Methods 34:125-133.

Colle I.M, Wise RA (1988) Effects of nucleus accumbens amphetamine on lateral hypothalamic brain stimulation reward. Brain Res 459: 361-368.

Deadwyler SA, Biela J, Rose G, West MO, Lynch G (1979) A microdrive for use with glass or metal microelectrodes in recording from freely-moving rats. Electroencephalogr Clin Neurophysiol 47:752754.

DeFrance JF, Marchand JF, Sikes RW, Chronister RB, Hubbard JI (1985) Characterization of fimbria input to nucleus accumbens. $J$ Neurophysiol 54:1553-1567.

Delfs JM, Schreiber L, Kelley AE (1990) Microinjection of cocaine into the nucleus accumbens elicits locomotor activation in the rat. $J$ Neurosci 10:303-310. 
Di Chiara G, Imperato A (1988) Drugs abused by humans preferentially increase synaptic dopamine concentrations in the mesolimbic system of freely moving rats. Proc Natl Acad Sci USA 85:5274-5278. Freund TF, Powell JF, Smith AD (1984) Tyrosine hydroxylase-immunoreactive boutons in synaptic contact with identified striatonigral neurons, with particular reference to dendritic spines. Neuroscience 13:1189-1215.

Fuller JH, Schlag JD (1976) Determination of antidromic excitation by the collision test: problems of interpretation. Brain Res 112:283298.

Gallistel CR, Shizgal P, Yeomans JS (1981) A portrait of the substrate for self-stimulation. Psychol Rev 88:228-273.

Gallistel CR, Gomita Y, Yadin E, Campbell KA (1985) Forebrain origins and terminations of the medial forebrain bundle metabolically activated by rewarding stimulation or reward-blocking doses of pimozide. J Neurosci 5:1246-1261.

Gomita Y, Gallistel CR (1982) Effects of reinforcement-blocking doses of pimozide on neural systems driven by rewarding stimulation of the MFB: a ${ }^{14} \mathrm{C}$-2-deoxyglucose analysis. Pharmacol Biochem Behav 17:841-845.

Gratton A, Hoffer BJ, Gerhardt GA (1988) Effects of electrical stimulation of brain reward sites on release of dopamine in rat: an in vivo electrochemical study. Brain Res Bull 21:319-324.

Groenewegen HJ, Vermeulen-Van der Zee E, Te Kortschot A, Witter MP (1987) Organization of the projections from the subiculum to the ventral striatum in the rat. A study using anterograde transport of Phaseolus vulgaris leucoagglutinin. Neuroscience 23:103-120.

Hakan RL, Henriksen SJ (1989) Opiate influences on nucleus accumbens neuronal electrophysiology: dopamine and non-dopaminc mechanisms. J Neurosci 9:3538-3546.

Hernandez L, Hoebel BG (1988) Food reward and cocaine increase extracellular dopamine in the nucleus accumbens as measured by microdialysis. Life Sci 42:1705-1712.

Hoebel BG, Monaco AP, Hernandez L, Aulisi EF, Stanley BG, Lenard L (1983) Self-injection of amphetamine directly into the brain. Psychopharmacology 81:158-163.

Joseph MH, Hodges H (1990) Lever pressing for food reward and changes in dopamine turnover and uric acid in rat caudate and nucleus accumbens studied chronically by in vivo voltammetry. J Neurosci Methods 34:143-149.

Kelley AE, Gauthier AM, Lang CG (1989) Amphetamine microinjections into distinct striatal subregions cause dissociable effects on motor and ingestive behavior. Behav Brain Res 35:27-39.

Lipski J (1981) Antidromic activation of neurones as an analytic tool in the study of the central nervous system. J Neurosci Methods 4:132 .

Lopes da Silva FH, Arnolds DEAT, Neijt HC (1984) A functional link between the limbic cortex and ventral striatum: physiology of the subiculum accumbens pathway. Exp Brain Res 55:205-214.

Lyness WH, Friedle NM, Moore KE (1979) Destruction of dopaminergic nerve terminals in nucleus accumbens: effect on $d$-amphetamine self-administration. Pharmacol Biochem Behav 11:553-556.

Maeda H, Mogenson GJ (1980) An electrophysiological study of inputs to neurons of the ventral tegmental area from the nucleus accumbens and medial preoptic anterior hypothalamic areas. Brain Res 197:365-377.

Mogenson GJ (1987) Limbic-motor integration. Prog Psychobiol Physiol Psychol 12:117-170.

Nakahara D, Ozaki N, Miura Y, Miura H, Nagatsu T (1989) Increased dopamine and serotonin metabolism in the rat nucleus accumbens produced by intracranial self-stimulation of medial forebrain bundle as measured by in vivo microdialysis. Brain Res 495:178-181.

Nauta WJH, Smith GP, Faull RLM, Domesick VB (1978) Efferent connections and nigral afferents of the nucleus accumbens septi in the rat. Neuroscience $3: 385-401$.

Nieuwenhuys R, Geeraedts LMG, Veening JG (1982) The medial forebrain bundle of the rat: I. General introduction. J Comp Neurol 206:49-81.

Olds J, Milner P (1954) Positive reinforcement produced by electrical stimulation of septal area and other regions of rat brain. J Comp Physiol Psychol 45:555-564.

Paxinos G, Watson C (1986) The rat brain in stereotaxic coordinates, 2d ed. New York: Academic.

Pettit HO, Ettenberg A, Bloom FE, Koob GF (1984) Destruction of dopamine in the nucleus accumbens sclectively attenuates cocaine but not heroin self-administration in rats. Psychopharmacology 84 : 167-173.

Phillips AG, Jakubovic A, Fibiger HC (1987) Increased in vivo tyrosine hydroxylase activity in rat telencephalon produced by self-stimulation of the ventral tegmental area. Brain Res 402:109-116

Porrino LJ, Huston-Lyons D, Bain G, Sokolotf L, Kornetsky C (1990) The distribution of changes in local cerebral energy metabolism associated with brain stimulation reward to the medial forebrain bundle of the rat. Brain Res 511:1-6.

Prado-Alcala R, Wise RA (1984) Brain stimulation reward and dopamine terminal fields. I. Caudate-putamen, nucleus accumbens and amygdala. Brain Res 297:265-273.

Radhakishun FS, van Ree JM, Westerink BHC (1988) Scheduled eating increases dopaminc rclcase in the nucleus accumbens of fooddeprived rats as assessed with on-line brain dialysis. Neurosci Lett 85:351-356.

Roberts DCS, Koob GF, Klonoff P, Fibiger HC (1980) Extinction and recovery of cocaine self-administration following 6-hydroxydopamine lesions of the nucleus accumbens. Pharmacol Biochem Behav 12:781-787.

Rolls ET (1971a) Involvement of brainstem units in medial forebrain bundle self-stimulation. Physiol Behav 7:297-310.

Rolls ET (1971b) Contrasting effects of hypothalamic and nucleus accumbens septi self-stimulation on brain stem single unit activity and cortical arousal. Brain Res 31:275-285.

Rompre P-P, Shizgal P (1986) Electrophysiological characteristics of neurons in forebrain regions implicated in self-stimulation of the medial forcbrain bundle in the rat. Brain Res 364:338-349.

Ryan LJ, Young SJ, Groves PM (1986) Substantia nigra stimulation evoked antidromic responses in rat neostriatum. Exp Brain Res 63: $449-460$.

Ryan LJ, Diana M, Young SJ, Groves PM (1989) Dopamine DI heteroreceptors on striatonigral axons are not stimulated by endogenous dopamine either tonically or after amphetamine: evidence from terminal excitability. Exp Brain Res 77:161-165.

Segal M, Bloom FE (1976) The action of norepinephrine in the rat hippocampus. III. Hippocampal cellular responses to locus coeruleus stimulation in the awake rat. Brain Res 107:499-511.

Sesack SR, Pickel VM (1990) In the rat medial nucleus accumbens, hippocampal and catecholaminergic terminals converge on spiny neurons and are in apposition to each other. Brain Res 527:266-279.

Shizgal P, Schindler D, Rompre P-P (1989) Forebrain neurons driven by rewarding stimulation of the medial forebrain bundle in the rat: comparison of psychophysical and electrophysiological estimates of refractory periods. Brain Res 499:234-248.

Smith AD, Bolam JP (1990) The neural network of the basal ganglia as revealed by the study of synaptic connections of identified structures. Trends Neurosci 13:259-265.

Somogyi P, Bolam JP, Smith AD (1981) Monosynaptic cortical input and local axon collaterals of identified striatonigral neurons. A light and electron microscopic study using the Golgi-peroxidase transportdegeneration procedure. J Comp Neurol 195:567-584.

Stellar JR, Corbett D (1989) Regional neuroleptic microinjections indicate a role for nucleus accumbens in lateral hypothalamic selfstimulation reward. Brain Res 477:126-143.

Taylor JR, Robbins TW (1984) Enhanced behavioural control by conditioned reinforcers following microinjections of $d$-amphetamine into the nucleus accumbens. Psychopharmacology 84:405-412.

Taylor JR, Robbins TW (1986) 6-Hydroxydopamine lesions of the nucleus accumbens, but not of the caudate nucleus, attenuate enhanced responding with reward-related stimuli produced by intraaccumbens $d$-amphetamine. Psychopharmacology 90:390-397.

Thierry AM, Deniau JM, Herve D, Chevalier G (1980) Electrophysiological evidence for non-dopaminergic mesocortical and mesolimbic neurons in the rat. Brain Res 201:210-214.

Totterdell S, Smith AD (1989) Convergence of hippocampal and dopaminergic input onto identified neurons in the nucleus accumbens of the rat. J Chem Neuroanat 2:285-298.

Trowill JA, Panksepp J, Gandelman R (1969) An incentive model of rewarding brain stimulation. Psychol Rev 76:264-281.

Ungerstedt U (1971) Stereotaxic mapping of the monoamine pathways in the rat brain. Acta Physiol Scand [Suppl] 367:1-48.

Walaas I, Fonnum F (1980) Biochemical evidence for gamma-ami- 
nobutyrate containing fibres from the nucleus accumbens to the substantia nigra and ventral tegmental area in the rat. Neuroscience 5: $63-72$.

West MO, Wolske M (1987) Electrophysiological characterization of single unit activity in the nucleus accumbens of the freely moving rat. Soc Neurosci Abstr 14:923.

West MO, Woodward DJ (1984) A technique for microiontophoretic study of single neurons in the freely moving rat. J Neurosci Methods 11:179-186.

White FJ, Wang RY (1986) Electrophysiological evidence for the existence of both D-1 and D-2 dopamine receptors in the rat nucleus accumbens. J Neurosci 6:274-280.

Wise RA (1980) Action of drugs of abuse on brain reward systems. Pharmacol Biochem Behav 13[Suppl 1]:213-223.

Wise RA, Rompre P-P (1989) Brain dopamine and reward. Annu Rev Psychol 40:191-225.

Wolske M, Rompre P-P, Wise RA, West MO (1990) Nucleus accumbens single unit activity in the rat during VTA self-stimulation. Soc Neurosci Abstr 16:592.

Yang CR, Mogenson GJ (1986) Dopamine enhances terminal excit- ability of hippocampal-accumbens neurons via D2 receptor: role of dopamine in presynaptic inhibition. J Neurosci 6:2470-2478.

Yeomans JS (1979) Absolute refractory periods of self-stimulation neurons. Physiol Behav 22:911-919.

Yeomans IS (1982) The cells and axons mediating medial forebrain bundle reward. In: The neural basis of feeding and reward (Hoebel BG, Novin D, eds), pp 405-417. Brunswick, ME: Haer Institute.

Yeomans JS (1989) Two substrates for medial forebrain bundle selfstimulation: myelinated axons and dopamine axons. Neurosci Biobehav Rev 13:91-98.

Yeomans JS, Maidment NT, Bunney BS (1988) Excitability properties of medial forebrain bundle axons of $A 9$ and $A 10$ dopamine cells. Brain Res 450:86-93.

Yim CY, Mogenson GJ (1980a) Electrophysiological studies of neurons in the ventral tegmental area of Tsai. Brain Res 181:301-313.

Yim CY, Mogenson GJ (1980b) Effect of picrotoxin and nipecotic acid on inhibitory response of dopaminergic neurons in the ventral tegmental area to stimulation of the nucleus accumbens. Brain Res 199:466-472. 